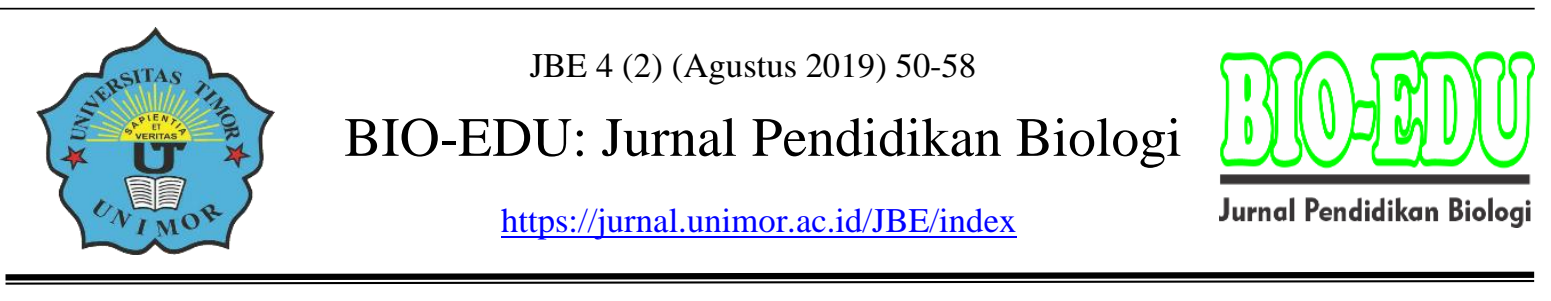

\title{
Keanekaragaman Kupu-Kupu (Lepidoptera) di Sekitar Pinggiran Sungai Maslete Kabupaten Timor Tengah Utara
}

\author{
Maria Mathilda Nino \\ Program Studi Pendidikan Biologi, Universitas Timor \\ Email: ninomariamatilda@gmail.com
}

DOI: $\underline{\text { https://doi.org/10.32938/jbe.v4i2.386 }}$

\begin{abstract}
Abstrak
Penelitian tentang keanekaragaman kupu-kupu sudah banyak dilakukan khususnya di pulau Jawa, namun belum semua wilayah di Indonesia diperoleh data tentang keanekaragaman kupu-kupu. Salah satu di Kabupaten Timor Tengah Utara masih belum banyak dilakukan, khususnya di sekitar pinggiran sungai Maslete, Kabupaten Timor Tengah Utara. Tujuan dari penelitian ini adalah untuk mengetahui jenis-jenis kupu-kupu, untuk mengetahui keanekaragaman kupu-kupu, untuk mengetahui faktor-faktor lingkungan yang mempengaruhi kehidupan kupukupu di sekitar pinggiran sungai Maslete Kabupaten Timor Tengah Utara serta untuk mengetahui implementasi hasil penelitian dalam pembelajaran biologi di sekolah. Metode yang digunakan dalam penelitian ini yaitu metode jelajah. Penentuan lokasi pengambilan sampel dilakukan dengan metode purposive sampling. Pengambilan sampel dilakukan dengan mengikuti garis transek sepanjang $500 \mathrm{~m}$, Pada garis transek dibuat substransek. Jarak antar subtransek yaitu $250 \mathrm{~m}$. Pada masing-masing subtransek dibuat 2 buah plot berukuran $5 \times 5 \mathrm{~m}^{2}$. Kupu-kupu ditangkap menggunakan jaring dan identifikasi berdasarkan cirri morfologi kupu-kupu. Data yang diperoleh dianalisis keanekaragamannya menggunakan indeks keanekaragaman Shannon-wienner. Hasil penelitian di sekitar pinggiran sungai maslete ditemukan 7 jenis kupu-kupu yang tergolong dalam 3 famili yaitu Pieridae dengan 3 jenis, Nymphalidae dengan 2 jenis dan Papilionidae dengan 2 jenis. Indeks keanekaragaman kupu-kupu di sekitar pinggiran sungai maslete tergolong rendah dengan nilai H' 0,9884. Hasil pengukuran parameter lingkungan di sekitar pinggiran sungai Maslete menunjukkan bahwa suhu udara berkisar antara $34,37-34,67^{\circ} \mathrm{C}$ dan kelembaban udara berkisar antara 57-59\%.
\end{abstract}

Kata kunci : Keanekaragaman, kupu-kupu, sungai

\begin{abstract}
Research on butterfly diversity has been carried out, especially in Java, but not all regions in Indonesia have obtained data on butterfly diversity. One in the North Central Timor Regency is still not much done, especially around the banks of the river Maslete, North Central Timor Regency. The purpose of this study was to determine the types of butterflies, to know the diversity of butterflies, to determine environmental factors that affect the life of butterflies around the banks of the river Maslete, North Central Timor Regency and to determine the implementation of research results in learning biology in school. The method used in this study is the roaming method. Determination of sampling locations is done by purposive sampling method. Sampling was carried out by following a $500 \mathrm{~m}$ transect line, the transect line was made on the transect line. The distance between subtransects is $250 \mathrm{~m}$. In each subtransect, 2 plots of $5 \times 5 \mathrm{~m} 2$ were made. Butterflies are captured using nets and identification is based on the morphological characteristics of the butterfly. The data obtained were analyzed for diversity using the Shannon-wienner diversity index. The results of research around the banks of the river
\end{abstract}


maslete found 7 types of butterflies belonging to 3 families namely Pieridae with 3 types, Nymphalidae with 2 types and Papilionidae with 2 types. The index of butterfly diversity around the banks of the Maslete River is relatively low with an $\mathrm{H}$ value of 0.9884 . The results of measurements of environmental parameters around the Maslete riverbanks show that air temperatures range between $34.37-34.67 \mathrm{o} \mathrm{C}$ and humidity ranges between 57$59 \%$.

Keywords: Diversity, butterflies, rivers

\section{PENDAHULUAN}

Indonesia merupakan negara yang memiliki keanekaragaman jenis tumbuhan maupun hewan yang sangat tinggi, sehingga Indonesia sering disebut sebagai salah satu pusat megabiodiversity dunia. Indonesia merupakan negara ke dua yang memiliki jenis kupu-kupu terbanyak di dunia, dengan jumlah jenis lebih dari 2000 jenis yang tersebar di seluruh nusantara (Amir, et al. 2008).

Kupu-kupu merupakan bagian dari keanekaragaman hayati yang harus dijaga kelestariannya dari kepunahan maupun penurunan keanekaragaman jenis. Secara ekologis kupu-kupu mempertahankan keseimbangan ekosistem dan memperkaya keanekaragaman hayati di alam (Rizal, 2007). Saat ini kupu-kupu menghadapi ancaman kepunahan yang disebabkan oleh alih fungsi lahan dihabitatnya (Soehartono, et al. 2003). Jumlah kupu-kupu secara umum tergantung pada pengelolaan suatu lahan. Menurut Handayani,et al., (2012) keanekaragaman jenis kupu-kupu yang tinggi dan penyebaran kupu-kupu dalam suatu wilayah dipengaruhi oleh faktor biotik dan abiotik dari suatu lingkungan.

Jumlah kupu-kupu terbanyak ditemukan di hutan lindung, hutan yang sudah diolah, dan padang rumput (Sundufu, et al. 2008). Sepanjang aliran sungai akan ditemukan jenisjenis kupu-kupu karena kupu-kupu mengisap air mineral dari pasir/ batu.

Kabupaten Timor Tengah Utara (TTU) merupakan daerah daratan dengan luas $2.669,70 \mathrm{~km}^{2}$ dari luas daratan Provinsi Nusa Tenggara Timur (NTT).

Sungai Maslete adalah salah satu sungai yang berada di Kabupaten TTU. Sungai Maslete terletak di Kecamatan Kota Kefamenanu. Sekitar pinggiran sungai Maslete terdapat tumbuh-tumbuhan yang merupakan pakan kupu-kupu sehingga tempat ini menjadi salah satu habitat kupu-kupu.

Penelitian tentang keanekaragaman kupu-kupu sudah banyak dilakukan khususnya di pulau Jawa, namun belum semua wilayah di Indonesia diperoleh data tentang keanekaragaman kupu-kupu. Salah satudi Kabupaten Timor Tengah Utara masih belum banyak dilakukan, khususnya di sekitar pinggiran sungai Maslete, Kabupaten Timor Tengah Utara.

Berdasarkan uraian diatas, maka peneliti termotivasi untuk melakukan penelitian dengan judul: "Keanekaragaman Kupu-Kupu (Lepidoptera) di Sekitar Pinggiran Sungai Maslete Kabupaten Timor Tengah Utara".

\section{METODE}

\section{Lokasi dan Waktu Penelitian}

Penelitian meliputi beberapa tahapan yaitu penangkapan kupu-kupu dilakukan di sekitar pinggiran sungai Maslete, Kabupaten Timor Tengah Utara, identifikasi dan pengawetan kupu-kupu dilakukan di Laboratorium Pendidikan Biologi, Universitas Timor. 
Penelitian telah dilakukan pada tanggal 26 Februari 2019 sampai dengan tanggal 29 Maret 2019.

\section{Rancangan Penelitian}

Penelitian ini merupakan penelitian eksploratif dengan menggunakan metode jelajah, dengan tahapan penelitian sebagai berikut: 1.) Mengadakan observasi ke lokasi penelitian. 2.) Persiapan awal penelitian. 3.) Penentuan batas daerah penelitian. 4.) Pengukuran suhu udara dan kelembaban udara lokasi penelitian. 5.) Penangkapan kupu-kupu. 6.) Proses identifikasi. 7.) Pengawetan kupu-kupu.

\section{Alat dan Bahan Penelitian}

Alat

Alat-alat yang digunakan dalam penelitian ini adalah :

a. Jaring kupu-kupu digunakan sebagai alat penangkap kupu-kupu.

b. Amplop digunakan sebagai tempat spesimen.

c. Kamera digunakan sebagai pendokumentasian.

d. Meteran digunakan untuk mengukur luas areal penelitian.

e. Gunting digunakan untuk menggunting bahan-bahan yang digunakan dalam penelitian.

f. Jarum suntik digunakan untuk menyuntikkan alkohol pada jenis kupu-kupu yang ditemukan untuk pengawetan spesimen.

g. Papan perentang digunakan untuk merentangkan sayap kupu-kupu.

h. Jarum pentul digunakan untuk mengatur posisi sayap saat direntangkan diatas papan perentang.

i. Alat tulis digunakan sebagai pencatatan data penelitian.

j. Thermohigrometer digunakan sebagai pengukuran suhu dan kelembaban udara.

k. Oven digunakan untuk mengeringkan kupu-kupu.

1. Gabus digunakan untuk meletakkan spesimen yang telah diawetkan.

Bahan

Bahan yang digunakan dalam penelitian ini adalah:

a. Kupu-kupu hasil koleksi.

b. Alkohol $70 \%$.

c. Buku panduan identifikasi kupu-kupu.

\section{Populasi dan Sampel Penelitian}

Populasi dalam penelitian ini adalah semua jenis kupu-kupu yang ada di sekitar pinggiran sungai Maslete, Kabupaten Timor Tengah Utara. Sampel dalam penelitian ini adalah jenis kupu-kupu yang didapatkan di jalur pengamatan yang telah ditentukan sepanjang 500m di sekitar pinggiran sungai Maslete, Kabupaten Timor Tengah Utara.

\section{Metode Pengumpulan Data}

a. Penentuan lokasi pengambilan sampel.

Penentuan lokasi pengambilan sampel dilakukan dengan metode purposive sampling. Pengambilan sampel dilakukan dengan mengikuti garis transek sepanjang 500m. Pada 
garis transek dibuat subtransek. Jarak antar subtransek $250 \mathrm{~m}$. Pada masing-masing subtransek dibuat 2 buah plot berukuran $5 \times 5 \mathrm{~m}^{2}$.

b. Pengukuran suhu udara dan kelembaban udara.

Pengukuran suhu udara dan kelembaban udara menggunakan thermohigrometer.

c. Pengumpulan sampel kupu-kupu

Pengumpulan spesimen kupu-kupu menggunakan metode jelajah dan penangkapan dilakukan dengan menggunakan jaring.

\section{Teknik Analisis Data}

Untuk menentukan nilai keanekaragaman jenis, dihitung dengan menggunakan indeks keanekaragaman Shannon-Wiener (Syahputra, 2015), sebagai berikut:

$$
\mathbf{H}^{\prime}=-\sum \mathbf{P i} \operatorname{Ln} \mathbf{P i}
$$

Dengan $\mathrm{Pi}=\mathrm{ni} / \mathrm{N}$

Untuk mengetahui keberadaan nilai keanekaragaman, maka indeks keanekaragaman Shannon-Wiener dikategorikan kedalam tiga kriteria, yaitu:

$\mathrm{H}^{\prime}<1=$ indeks keanekaragaman dikategorikan rendah.

$\mathrm{H}^{\prime}$ 1-3 = indeks keanekaragaman dikategorikan sedang.

$\mathrm{H}^{\prime}>3$ =indeks keanekaragaman dikategorikan tinggi.

\section{HASIL DAN PEMBAHASAN}

\section{Jenis-jenis kupu-kupu yang ditemukan di sekitar pinggiran sungai Maslete}

Berdasarkan data hasil penelitian di sekitar pinggiran sungai Maslete ditemukan 7 jenis kupukupu. Jumlah jenis kupu-kupu yang ditemukan dapat dilihat pada tabel 1.

Tabel 1. Jenis kupu-kupu yang ditemukan di sekitar pinggiran sungai Maslete

\begin{tabular}{|c|c|c|c|}
\hline No. & Family & Jenis & $\begin{array}{l}\text { Jumlah } \\
\text { Individu }\end{array}$ \\
\hline 1. & \multirow{3}{*}{ Pieridae } & Catopsilia pomona & 91 \\
\hline 2. & & Eurema hecabe & 28 \\
\hline 3. & & Catopsilia scylla & 4 \\
\hline 4. & \multirow[b]{2}{*}{ Nymphalidae } & Agraulis vanillae & 100 \\
\hline 5. & & Danaus chrysippus & 6 \\
\hline 6. & \multirow[b]{2}{*}{ Papilionidae } & Graphium Agamemnon & 2 \\
\hline 7. & & Papilio polytes & 1 \\
\hline \multicolumn{3}{|c|}{ Jumlah } & 232 \\
\hline
\end{tabular}

Berdasarkan tabel 1, menunjukkan bahwa pada lokasi penelitian di temukan kupukupu sebanyak 232 individu, yang terdiri dari 3 family dan 7 jenis, yang memiliki jumlah individu kupu-kupu mulai dari yang tertinggi sampai yang terendah adalah sebagai berikut: 
Agraulis vanillae adalah jenis yang paling banyak ditemukan di lokasi penelitian dengan jumlah individu sebanyak 100 individu. Kemudian di ikuti oleh Catopsilia pomona dengan jumlah individu sebanyak 91 individu. Eurema hecabe dengan jumlah individu sebanyak 28 individu. Danaus chrysippus dengan jumlah individu sebanyak 6 individu. Catopsilia scylla dengan jumlah individu sebanyak 4 individu. Graphium agamemnon dengan jumlah individu sebanyak 2 individu. Papilio polytes merupakan jenis yang paling sedikit ditemukan dengan jumlah individu 1.

Jenis kupu-kupu di sekitar pinggiran sungai Maslete didominasi oleh Agraulis vanillae dari family Nymphalidae, dengan jumlah individu sebanyak 100 individu. Tingginya populasi jenis Agraulis vanillae karena daerahnya terbuka dan adanya vegetasi yang sesuai untuk keberlangsungan hidup kupu-kupu tersebut. Tanaman inang dari family Nymphalidae diantaranya yaitu dari family Annonaceae, Malvaceae, Tiliaceae, Rutaceae, Sapindaceae, Anacardiaceae, Leguminoceae, Melastomataceae, Passifloraceae, Rubiaceae, Acanthaceae, Loranthaceae, Euphorbiaceae, Moraceae, dan beberapa lainnya (Corbet et al., 1956).
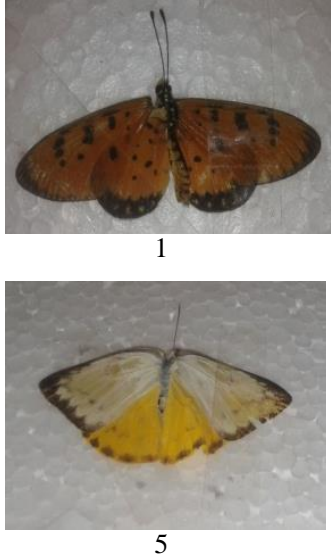
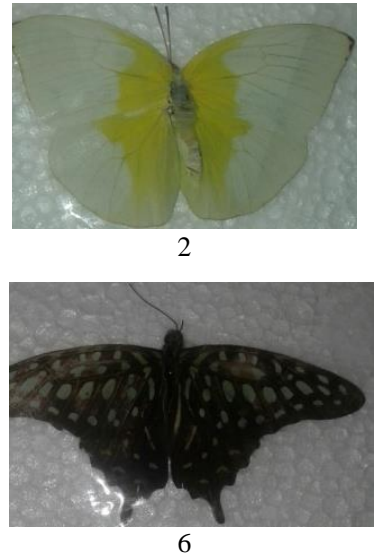
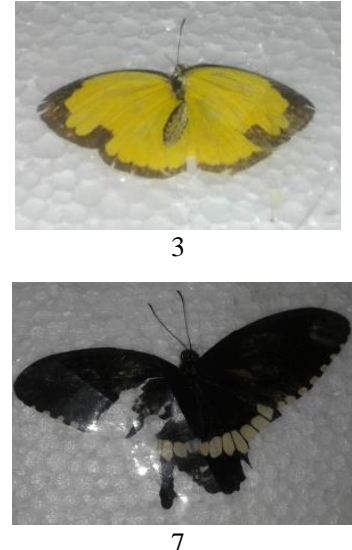

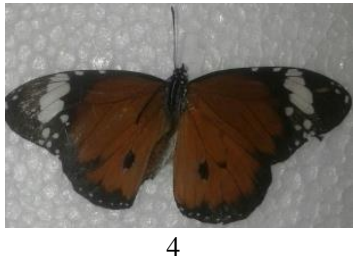

Gambar 1. Jenis-jenis kupu-kupu yang ditemukan di sekitar pinggiran sungai Maslete. 1) Agraulis vanillae; 2) Catopsilia pomona; 3) Eurema hecabe; 4)Danaus chrysippus; 5) Catopsilia scylla; 6)Graphium agamemnon; 7) Papilio polytes

Keanekaragaman Jenis Kupu-Kupu Berdasarkan Indeks Shannon-Wiener.

Berdasarkan hasil penelitian dan analisis perhitungan indeks nilai keanekaragaman jenis kupu-kupu pada lokasi sekitar pinggiran sungai Maslete dapat dilihat pada tabel 2.

Tabel 4.2 Nilai keanekaragaman jenis kupu-kupu di sekitar pinggiran sungai Maslete berdasarkan Indeks Shannon-Wiener

\begin{tabular}{|l|l|c|l|}
\hline No. & \multicolumn{1}{|c|}{ Jenis } & Nilai Keanekaragaman & Kategori \\
\hline 1. & Agraulis vanillae & 1,6881 & Sedang \\
\hline 2. & Catopsilia pomona & 1,5371 & Sedang \\
\hline 3. & Eurema hecabe & 1,6069 & Sedang \\
\hline 4. & Danaus chrysippus & 1,0114 & Sedang \\
\hline 5. & Catopsilia scylla & 1,0397 & Sedang \\
\hline
\end{tabular}




\begin{tabular}{|l|l|c|l|}
\hline 6. & Graphium agamemnon & 0 & Rendah \\
\hline 7. & Papilio polytes & 0 & Rendah \\
\hline \multicolumn{2}{r|}{ Rata-rata } & $\mathbf{0 , 9 8 8 4}$ & Rendah \\
\hline
\end{tabular}

Keanekaragaman dari ketujuh jenis kupu-kupu yang ditemukan di sekitar pinggiran sungai Maslete adalah sebagai berikut: Agraulis vanillae dengan nilai keanekaragaman sebesar 1,6881 dengan kategori sedang. Catopsilia pomona dengan nilai keanekaragaman sebesar 1,5371 dengan kategori sedang. Eurema hecabedengan nilai keanekaragaman sebesar 1,6069 dengan kategori sedang. Danaus chrysippus dengan nilai keanekaragaman sebesar 1,0114 dengan kategori sedang. Catopsilia scylla dengan nilai keanekaragaman sebesar 1,0397 dengan kategori sedang. Graphium agamemnon dengan nilai keanekaragaman 0 dengan kategori rendah. Papilio polytes dengan nilai keanekaragaman 0 dengan kategori rendah.Perbedaan nilai keanekaragaman jenis kupu-kupu yang ditemukan karena setiap jenis kupu-kupu memiliki jenis tumbuhan inang yang berbeda-beda.

Rata-rata nilai keanekaragaman dari ketujuh jenis kupu-kupu yang ditemukan adalah 0,9884. Nilai tersebut menunjukkan bahwa indeks keanekaragaman di sekitar pinggiran sungai Maslete masuk ke dalam kategori rendah berdasarkan kriteria nilai indeks keanekaragaman Shannon-Wiener.

Hal ini disebabkan karena pada penelitian yang dilakukan disekitar pinggiran sungai Maslete didapatkan sedikit jenis kupu-kupu. Keanekaragaman jenis suatu komunitas tinggi jika komunitas itu disusun oleh banyak jenis. Sebaliknya suatu komunitas dikatakan memiliki keanekaragaman jenis yang rendah jika komunitas itu disusun oleh sedikit jenis dan hanya sedikit jenis yang dominan (Indriyanto, 2006).

\section{Faktor Lingkungan Yang Mempengaruhi Kehidupan Kupu-Kupu}

Perhitungan terhadap faktor lingkungan di sekitar pinggiran sungai Maslete dapat dilihat pada tabel 3 berikut:

Tabel 3. Faktor lingkungan di sekitar pinggiran sungai Maslete

\begin{tabular}{|c|c|c|c|}
\hline Subtransek & Plot & $\begin{array}{c}\text { Suhu } \\
\left(\mathbf{0}^{\mathbf{C})}\right.\end{array}$ & $\begin{array}{c}\text { Kelembaban } \\
(\mathbf{\%})\end{array}$ \\
\hline I & 1 & 34,39 & 58 \\
& 2 & 34,56 & 57 \\
\hline II & 1 & 34,37 & 59 \\
& 2 & 34,38 & 58 \\
\hline III & 1 & 34,67 & 59 \\
& 2 & 34,65 & 58 \\
\hline
\end{tabular}

Hasil pengukuran faktor penunjang kehidupan kupu-kupu di sekitar pinggiran sungai Maslete menunjukkan bahwa suhu udara di sekitar pinggiran sungai Maslete berkisar antara 34,37-34,67 ${ }^{\circ} \mathrm{C}$ dan kelembaban udara berkisar antara 57-59\%. Sesuai dengan kisaran suhu udara yang ada dapat dikatakan bahwa suhu udara tersebut baik untuk kehidupan kupu-kupu dan kisaran kelembaban udara tersebut tidak cocok untuk kehidupan kupu-kupu.

Hal ini sesuai dengan pendapat Achmad (2002) yang mengatakan kupu-kupu 
memerlukan suhu udara antara $30-35^{\circ} \mathrm{C}$, dankelembaban udara antara 64-94\%. Kisaran suhu dan kelembaban udara tersebut tidak membahayakan bagi kelangsungan hidup kupu-kupu, karena dengan kisaran suhu dan kelembaban yang sesuai, kupu-kupu dapat mengurangi penguapan cairan tubuhnya. Keadaan lingkungan yang demikian menyebabkan kupu-kupu dapat bertahan dalam waktu yang lama. Udara yang panas dan kering akan mempercepat penguapan cairan tubuh dan membahayakan kehidupan kupu-kupu, sehingga kupu-kupu yang berukuran besar dan sayapnya lebar umumnya tidak dapat bertahan lama di area ini, karena luas permukaan tubuh yang semakin besar akan memperbesar penguapan cairan tubuh.

Faktor biotik yang mempengaruhi kelimpahan dan persebaran kupu-kupu adalah tumbuhan yang menjadi tumbuhan inang (host plant) atau tumbuhan pakan (food plant) yang menyediakan nektar bagi kupu-kupu. Struktur vegetasi yang terdapat di lokasi pengamatan dapat mempengaruhi kelimpahan pada jenis kupu-kupu. Menurut Sharma et al., (2009), kompleksitas struktural habitat dan keragaman bentuk vegetasi berkorelasi dengan keragaman spesies serangga.

Tumbuhan yang sering dihinggapi kupu-kupu di lokasi penelitian adalah sebagai berikut: pecut kuda (Stachytarpheta jamaicensis), johar (Senna siamea), rambusa (Passiflora foetida), kerinyu (Eupatorium odoratum), gamal (Gliricidia sepium), pulutan (Urena lobato), pilang (Acacia leucophloea) dan rerumputan.

\section{Implementasi Penelitian Dalam Proses Pembelajaran Biologi}

Hasil penelitian keanekaragaman kupu-kupu di sekitar pinggiran sungai Maslete, Kabupaten Timor Tengan Utara dapat diimplementasikan pada proses pembelajaran biologi tingkat Sekolah Menengah Pertama (SMP) kelas VII pada materi Klasifikasi Makluk Hidup dan Sekolah Menengah Atas (SMA) kelas X pada materi tingkat keanekaragaman hayati. Acuan kurikulum yang digunakan dalam desain pembelajaran terkait dengan penelitian yang telah dilakukan adalah kurikulum 2013.

\section{KESIMPULAN DAN SARAN}

\section{Kesimpulan}

Kesimpulan pada penelitian ini adalah sebagai berikut:

1. Jenis kupu-kupu yang ditemukan sebanyak 232 individu, yang terdiri dari 3 family dan 7 jenis yaitu: Agraulis vanillae dengan jumlah individu sebanyak 100 individu, Catopsilia pomona dengan jumlah individu sebanyak 91 individu, Eurema hecabe dengan jumlah individu sebanyak 28 individu, Danaus chrysippus dengan jumlah individu sebanyak 6 individu, Graphium agamemnon dengan jumlah individu sebanyak 2 individu dan Papilio polytes dengan jumlah individu 1.

2. Nilai keanekaragaman jenis kupu-kupu di sekitar pinggiran sungai Maslete masuk kategori sedang dan rendah adalah sebagai berikut: Eurema hecabe dengan nilai keanekaragaman sebesar 1,6069 dengan kategori sedang, Catopsilia pomona dengan nilai keanekaragaman sebesar 1,5371 dengan kategori sedang, Catopsilia scylla dengan nilai keanekaragaman sebesar 1,0397 dengan kategori sedang, Agraulis vanillae dengan nilai keanekaragaman sebesar 1,6881 dengan kategori sedang, Danaus chrysippus dengan nilai 
keanekaragaman sebesar 1,0114 dengan kategori sedang, Papilio polytes dengan nilai keanekaragaman 0 dengan kategori rendah dan Graphium agamemnon dengan nilai keanekaragaman 0 dengan kategori rendah.

3. Hasil pengukuran parameter lingkungan di sekitar pinggiran sungai Maslete menunjukkan bahwa suhu udara berkisar antara $34,37-34,67^{\circ} \mathrm{C}$ dan kelembaban udara berkisar antar $57-59 \%$.

4. Hasil penelitian keanekaragaman kupu-kupu di sekitar pinggiran sungai Maslete, Kabupaten Timor Tengan Utara dapat diimplementasikan pada proses pembelajaran biologi tingkat Sekolah Menengah Pertama (SMP) kelas VII pada materi Klasifikasi Makluk Hidup dan Sekolah Menengah Atas (SMA) kelas X pada materi tingkat keanekaragaman hayati. Acuan kurikulum yang digunakan dalam desain pembelajaran terkait dengan penelitian yang telah dilakukan adalah kurikulum 2013.

\section{Saran}

Saran dari penelitian ini adalah sebagai berikut:

1. Masyarakat setempat, perlu adanya upaya pelestarian kupu-kupu baik kupu-kupu siang maupun kupu-kupu malam untuk mengurangi kepunahan.

2. Bagi peneliti selanjutnya, agar area penelitian dapat diperluaskan lagi sehingga memungkinkan ditemukannya jenis lebih banyak.

\section{DAFTAR RUJUKAN}

Achmad A. 2002. Potensi dan Sebaran Kuри-Kupu di Kawasan Taman Wisata Alam Bantimurung. Dalam: Workshop Pengelolaan Kupu-kupu Berbasis Masyarakat. Bantimurung.

Borror DJ, CA Triplehorn \& NF Jhonson. 1992. Pengenalan Pelajaran Serangga. Yogyakarta: Gadjah Mada University Press.

Deka J \& DK Sharma.2007. Keanekaragaman Hayati Dan Konservasi Dengan Referensi Khusus Bagi Satwa Dilindungi di Timur Laut Ind. Terjemahan. On line at http://id.shvoong.com.

Efendi. 2009. Keragaman Kupu-kupu (Lepidoptera: Ditrysia) di Kawasan "Hutan Koridor" Taman Nasional Gunung Halimun Salak Jawa Barat. Bogor: Institut Pertanian Bogor.

Fachrul, MF. 2012. Metode Sampling Bioekologi.PT Bumi Aksara. Jakarta.

Hadi,H.M., Udi, T.,Rully, R. 2009. Biologi Insekta Entomologi. Yogyakarta; Graha Ilmu.

Imes,R. 1992. The Practical Entomologis; An Introduction Guide to Observing and Understanding the World of Insects. Quarto Publishing Inc. New York.

Indriyanto. 2006. Ekologi Hutan. Jakarta : PT Bumi Aksara.

Jumar. 2000. Entomologi Pertanian. PT Rineka Cipta. Jakarta.

Kunte, K. 2006. Butterflies of Peninsular India.Indian Academy of Sciences. Universities Press. India.

Landman, W. 2001.The Complete Encyclopedia of Butterflies.Grange Books. 
Mastrigt, H. V \& Rosariyanto, E. 2005.Buku Panduan Lapangan Kupu-kupu Untuk Wilayah Mamberamo Sampai Pegunungan Cyclops. Conservation International Indonesia. Jakarta.

Morrell. 1960. Malayan Nature Hanbook; Common Malayan Butterflies.Longman; Kuala Lumpur.

Noerdjito WA, Aswari P. 2003. Metode Survei dan Pemantauan Populasi Satwa: Seri Keетраt Кири-kири Papilionidae. Bogor: Pusat Penelitian dan Pengembangan Biologi-LIPI Cibinong.

Peggie D.,\& Amir M. 2006. Panduan Praktis Kupu-kupu di Kebun Raya Bogor. Bogor: Bidang Zoologi Pusat.

Rizal S. 2007. Populasi Кири-kupu di Kawasan Cagar Alam Rimbo Panti dan Kawasan Wisata Lubuk Minturun Sumatera Barat. Mandiri 9 (3): 177-237.

Scoble, M.J. 1995. The Lepidoptera: form, Function, and Diversity. Oxford University Press. New York.

Soekardi, H. 2007. Кири-kupu di kampus Unila.Penerbit Universitas Lampung. Lampung

Suhara (2009).Ordo Lepidoptera, Ngengat Dan Kupu-kupu.Bandung : UPI Publisher. 